\title{
Carcinoma de células acinares
}

\author{
Acinar cell carcinoma
}

\section{Raúl Díaz Iga,* Gloria Domínguez Fernández, ${ }^{\dagger}$ Selene Fernández Contreras ${ }^{\ddagger}$}

\section{RESUMEN}

El carcinoma de células acinares es una neoplasia epitelial maligna de glándulas salivales; es un tipo de adenocarcinoma formado por células acinares claras que describen un patrón sólido o folicular con escaso estroma visible. Estas células acinares pueden ser mucosas, serosas o mixtas. Es un tumor poco frecuente. Los carcinomas de glándulas salivales representan aproximadamente $0.6 \%$ de todas las neoplasias de la economía. El carcinoma de células acinares constituye de 1-6\% de estas neoplasias, representa alrededor de $2-4 \%$ de neoplasias primarias de glándulas parótidas, siendo ésta su ubicación más común, es infrecuente en glándulas salivales menores. Es la tercera neoplasia maligna, después del carcinoma adenoideo quístico y mucoepidermoide. Se trata de paciente masculino de 52 años, con tumoración en velo palatino que se extiende a pilar anterior amigdalino y mucosa alveolar retromolar inferior derecho de $3 \times 6 \mathrm{~cm}$ de dimensión. El diagnóstico histopatológico fue carcinoma de células acinares, originado de glándula salival menor.

Palabras clave: Carcinoma de células acinares, adenocarcinoma, carcinoma adenoide quístico, mucoepidermoide y glándula salival menor.

\section{ABSTRACT}

Acinar cell carcinoma is a malignant epithelial neoplasm of the salivary glands, being a type of adenocarcinoma formed by clear acinar cells that describe a solid or follicular pattern with little visible. These acinar cells can be mucous, serous, or mixed. It is a rare tumor. Salivary gland carcinomas represent approximately $0.6 \%$ of all malignancies in the economy. Acinar cell carcinoma constitutes $1-6 \%$ of these neoplasms, representing around $2-4 \%$ of primary parotid gland neoplasms, this being its most common location, being infrequent in minor salivary glands. It is the third malignancy, after adenoid cystic and mucoepidermoid carcinoma. 52-year-old man, with a palatine veil tumor that extended to the tonsillar anterior pillar and right inferior retromolar alveolar mucosa $3 \times 6 \mathrm{~cm}$ in size, the histopathological diagnosis was acinar cell carcinoma, originated from the minor salivary gland.

Keywords: Acinar cell carcinoma, adenocarcinoma, cystic adenoid carcinoma, mucoepidermoid and minor salivary gland.

* Servicio de Cirugía Bucal y Maxilofacial.

¥ Adjunto de Servicio de Cirugía Bucal y Maxilofacial.

Hospital Regional Minatitlán PEMEX.

\author{
Correspondencia: \\ Raúl Díaz Iga \\ E-mail: diaz_iga_r@hotmail.com
}

Citar como: Díaz IR, Domínguez FG, Fernández CS. Carcinoma de células acinares. Rev Mex Cir Bucal Maxilofac. 2021;17 (1): 11-16. https://dx.doi.org/10.35366/100255 


\section{INTRODUCCIÓN}

Los tumores de las glándulas salivales representan el $3 \%$ de todas las neoplasias benignas y malignas de cabeza y cuello. El carcinoma de células acinares en las glándulas salivales se origina como resultado de la proliferación neoplásica y citodiferenciación aberrante de células de reserva o madre pluripotenciales, que normalmente residen en la unión del acino con el conducto intercalado propio de las glándulas salivales maduras. ${ }^{1,2}$

El carcinoma de células acinares es poco frecuente, constituye de $1-6 \%$ de las neoplasias de glándulas salivales, con predominio en mujeres, puede aparecer a cualquier edad, ya que se han descrito casos desde niños hasta ancianos, pero la mayor evidencia ocurre en la quinta década de vida, con una edad promedio de 44 años (30 a 60), con una incidencia hombre-mujer de 1:2. Presenta una tasa de recurrencia entre 12 y $35 \% .^{1,3}$ Este tumor es la tercera entidad maligna epitelial de bajo grado más común de la glándula salival mayor después del carcinoma mucoepidermoide y el carcinoma adenoide quístico. . $^{4}$

La glándula parótida es el lugar de origen de más del $80 \%$ de los carcinomas de células acinares, es raro e inusual en otras glándulas salivales mayores y menores. ${ }^{1,5}$ Por lo general, la mayoría de los tumores de glándulas salivales menores se localizan en mucosa bucal y labio. Por lo que los carcinomas de células acinares que tienden a desarrollarse en el paladar son poco frecuentes.
Es considerada una neoplasia maligna de bajo grado, existen factores histológicos que tienen valor pronóstico, como son la invasión macroscópica, factores microscópicos de desmoplasia, atipia o actividad mitótica aumentada que son considerados predictores de progresión de la enfermedad. ${ }^{1,2}$

Patológicamente, las características celulares de tumores acinares se disponen de diversos patrones estructurales sólido, microquístico, papilar quístico y folicular. Estas características no poseen significado pronóstico. ${ }^{5,7,8}$

Batsakis ha descrito una gradación histológica del cáncer de células acinares, la cual identifica tres grados (Tabla 1).9-11

\section{REPORTE DE UN CASO}

Paciente de sexo masculino de 52 años de edad, que acude al Servicio de Cirugía Maxilofacial del Hospital Regional de Minatitlán PEMEX, referido del Servicio de Urgencias por presentar tumoración en paladar blando y en mucosa alveolar retromolar inferior del lado derecho, con aproximadamente una semana de evolución, con incremento de tamaño de manera gradual, presentando de inicio leve sintomatología a dolorosa, sin prestar disfagia o disnea.

A la exploración clínica se aprecia adecuada simetría facial, perfil recto, sin limitación a la apertura oral. Sin adenomegalias cervicales. Intraoralmente se observa tumoración de $3 \times 6 \mathrm{~cm}$ de dimensión, localizado en paladar blando que se proyecta a mucosa alveolar inferior retromolar y se extiende a

Tabla 1: Gradación histológica del carcinoma de células acinares (Batsakis).

\begin{tabular}{|c|c|c|}
\hline Grado I & Grado II & Grado III \\
\hline $\begin{array}{l}\text { Monolobular y circunscrito: puede } \\
\text { ser encapsulado; puede ser de origen } \\
\text { intraoral }\end{array}$ & $\begin{array}{l}\text { Lobulado o multifocal; menos circuns- } \\
\text { crito; no tiene cápsula }\end{array}$ & No circunscrito, infiltrativo \\
\hline Menor de $3 \mathrm{~cm}$ & 3 a $6 \mathrm{~cm}$ & Más de 6 cm \\
\hline $\begin{array}{l}\text { Sin compromiso de la porción profunda } \\
\text { de la parótida }\end{array}$ & $\begin{array}{l}\text { Compromiso de la porción profunda de } \\
\text { la parótida }\end{array}$ & $\begin{array}{l}\text { Compromiso de la porción profunda o } \\
\text { extensión extraparenquimatosa }\end{array}$ \\
\hline $\begin{array}{l}\text { Predominio de arquitectura sólida acinar } \\
\text { o microquística; formas microquísticas }\end{array}$ & $\begin{array}{l}\text { Diferenciación túbulo ductal de más de } \\
15 \text { a } 20 \% \text { de la arquitectura; arquitectu- } \\
\text { ra papiloquística neoplásica }\end{array}$ & $\begin{array}{l}\text { Laminas sincitiales indiferenciadas con o } \\
\text { sin patrones tubuloductales infiltrativos } \\
\text { menos diferenciados; formación quística } \\
\text { infrecuente; nunca macroquistes }\end{array}$ \\
\hline $\begin{array}{l}\text { Pleomorfismo nuclear o celular mínimo } \\
\text { o ausentes; ausencia de mitosis; ausen- } \\
\text { cia de propiedad invasiva, ausencia de } \\
\text { necrosis excepto para las formas macro- } \\
\text { quísticas regresivas }\end{array}$ & $\begin{array}{l}\text { Pleomorfismo nuclear y celular; mitosis } \\
\text { escasas; área sólida pueden mostrar } \\
\text { necrosis coagulativa o hemorragias; in- } \\
\text { vasión de pequeños nervios, pero nunca } \\
\text { prominentes; puede haber extensión } \\
\text { endovascular }\end{array}$ & $\begin{array}{l}\text { Componentes celulares son indiferencia- } \\
\text { dos con numerosas mitosis o invasivos } \\
\text { con formaciones tubuloductales pobre- } \\
\text { mente desarrolladas; invasión marcada } \\
\text { de vasos y nervios grandes y pequeños }\end{array}$ \\
\hline
\end{tabular}


pilar anterior amigdalino del lado derecho, indurado y no dolorosa a la palpación, de coloración violácea, con sangrado al menor estímulo, presenta área de necrosis tisular en el extremo derecho de la tumoración (Figura 1). El resto de la mucosa bien hidratada de color y consistencia normal, anodoncia parcial, prótesis fija metálica anterosuperior desajustada, mala higiene.

En la tomografía se aprecia tumoración palatina con una dimensión de $2 \times 3 \times 2 \mathrm{~cm}$, hipodensa y homogénea, de bordes no nítidos, desplazando ligeramente vía aérea hacia el lado izquierdo, no apreciando refuerzo de medio de contraste (Figuras 2 y 3 ).

Se efectúa nasofaringoscopia indirecta para valoración de la extensión tumoral, no se observa proyección tumoral en área nasal. Sus laboratorios prequirúrgicos se encuentran dentro de los parámetros normales.

Se le realiza toma de biopsia por aspiración con aguja fina y biopsia incisional bajo anestesia local con resultado histopatológico. La biopsia por aspiración con aguja fina muestra neoplasia de tipo epitelial. Mientras que la biopsia incisional evidencia tejido compatible con neoplasia de estirpe epitelial, morfológicamente sugiere adenocarcinoma de células acinares.

La intervención quirúrgica se basó en la toma de biopsia excisional, la cual se llevó a cabo bajo anestesia general balanceada. Se envía la muestra a examen histopatológico, se reporta tumor morfológicamente compatible con carcinoma de células acinares de glándula salival de tamaño $4 \times 3 \times 2 \mathrm{~cm}$, márgenes y lecho quirúrgico libre de lesión (Figuras 4 y 5).

Cursa con postoperatorio con dos eventos hemorrágicos que requirieron nuevamente realizar hemostasia bajo anestesia general.

Posterior a exéresis quirúrgica, el paciente recibió una sesión de quimioterapia y 30 sesiones de radioterapia, con seguimiento de seis, 12 y 24 meses sin recurrencia tumoral (Figura 6).

Histopatológicamente, estos tumores muestran una amplia gama de características histológicas, mostrando proliferación neoplásica maligna de células epiteliales de aspecto acinar con presencia de citoplasma basófilo, escasas mitosis dentro de una leve atipia dispuesta en mantos sólidos con permeación linfática y venosa (Figuras 7 a 10).

\section{DISCUSIÓN}

El carcinoma de células acinares fue descrito por primera vez por Nasse en 1892, siendo reconocido como un tumor poco común de glándulas salivales por Foote y Frazell en 1953. Por su relativo curso benigno se le denominó tumor de células acinares. Sin embargo, por su relativa habilidad a metástasis la Organización Mundial de la Salud estableció el término de "carcinoma de células acinares» en 1992. $6,12,13$

La patología tumoral de glándulas salivales representa tan sólo $3 \%$ de las neoplasias en la cabeza y el cuello. ${ }^{1,3}$ Conforma un grupo heterogéneo con variaciones raciales y geográficas, y discrepancia en incidencia respecto a sexo y edad. ${ }^{14}$

Las glándulas salivales mayores, encargadas de proveer la mayor parte del flujo salival de la cavidad oral a través de sus respectivos conductos, son las parótidas, las submaxilares y las sublinguales. Además, hay entre 600 y 1,000 glándulas salivales menores distribuidas en la lengua, amígdalas, faringe, paladar, cavidad nasal, senos paranasales, laringe y tráquea. El conjunto de glándulas salivales alcanza a producir entre 1,000 y $1,500 \mathrm{~cm}^{3}$ de saliva por día.

Los tumores salivales pueden desarrollarse en cualquiera de las glándulas salivales bajo el mismo patrón histológico. El $80 \%$ de los tumores salivales se presentan en la parótida, de 10 a $15 \%$ en la glándula submaxilar y entre cinco y $10 \%$ en la sublingual y glándulas salivales menores. La probabilidad que tiene un tumor de ser maligno es mayor cuanto menor sea el tamaño de la glándula salival en la que se asiente.

El carcinoma de células acinares se sitúa fundamentalmente en la parótida, es una neoplasia de bajo grado de malignidad, rara vez generan metástasis, pero evidencian una fuerte tendencia a recurrir que va de 12 a 35\%. Las tasas determinadas de supervivencia total van de $89 \%$ a cinco años y $56 \%$ a 20 años..$^{1,5}$

E. Omilie y colegas reportaron 21 casos de carcinoma de células acinares, localizados en mucosa bucal (siete casos), paladar (seis casos), labio superior (cinco casos), mucosa retromolar (dos casos) y labio inferior (un caso). ${ }^{8}$

El diagnóstico se establece con la anamnesis, biopsia por aspiración con aguja fina y apoyo de imagen (tomografía y ecografía). ${ }^{12}$ Nagel y su equipo mencionan que muchos reportes indican que la biopsia por aspiración con aguja fina de lesiones de glándulas salivales proporciona esencial información de diagnóstico; sin embargo, genera diagnósticos erróneos en neoplasias raras de glándulas salivales incluyendo el carcinoma de células acinares de glándulas salivales. ${ }^{15}$ 
Se ha observado que ni el patrón morfológico ni la composición celular son características útiles para emitir un pronóstico. Los signos desfavorables para el pronóstico incluyen dolor o fijación al tejido circundante, invasión macroscópica del tumor al tejido adyacente características microscópicas de desmoplasia, atipia celular y mayor actividad mitótica.

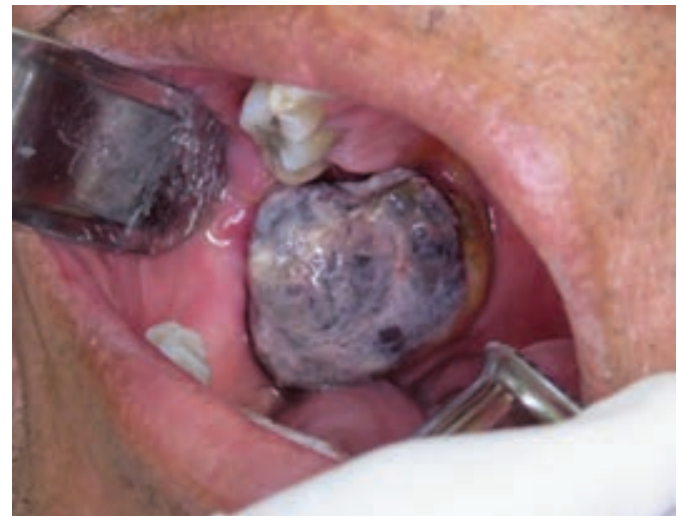

Figura 1: Lesión en región palatina y retromolar.
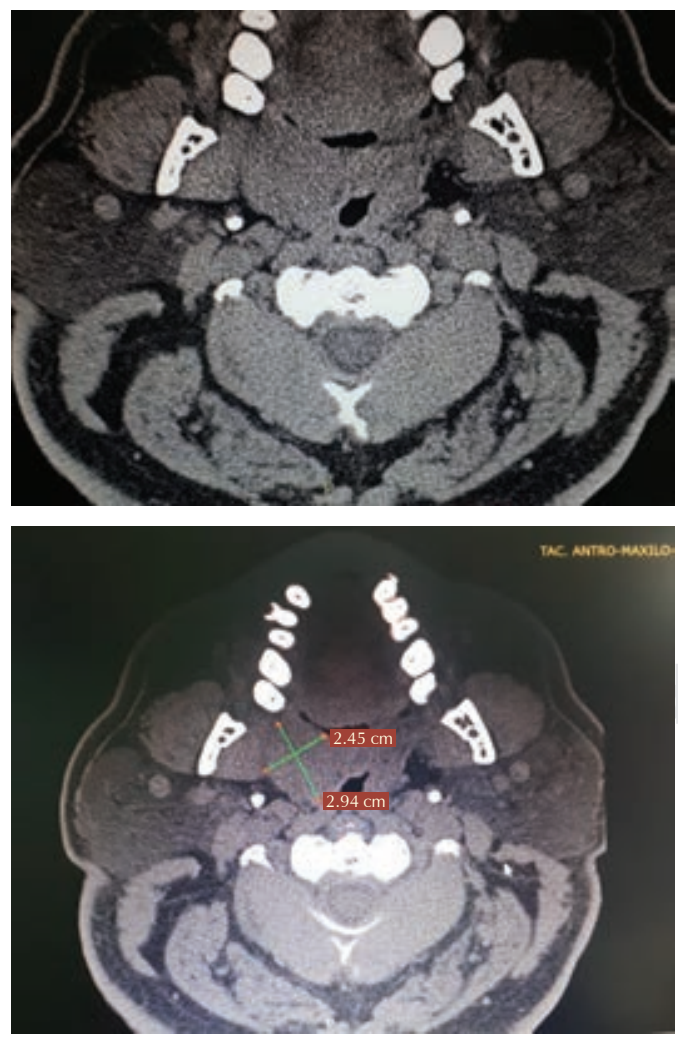

Figura 2: Corte tomográfico axial.

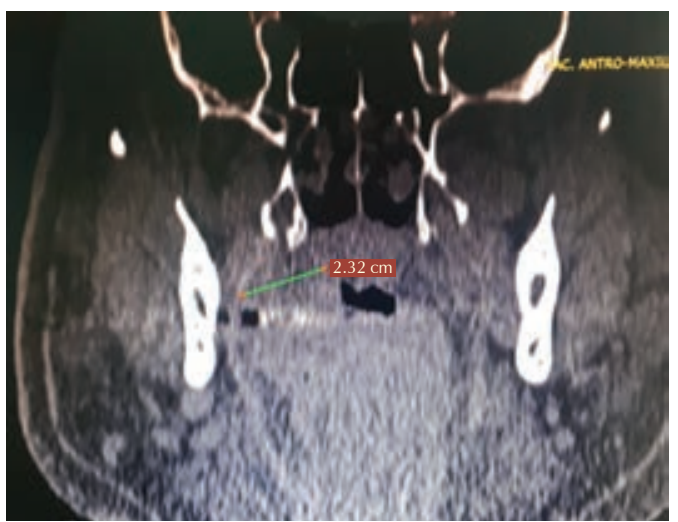

Figura 3: Corte tomográfico sagital.

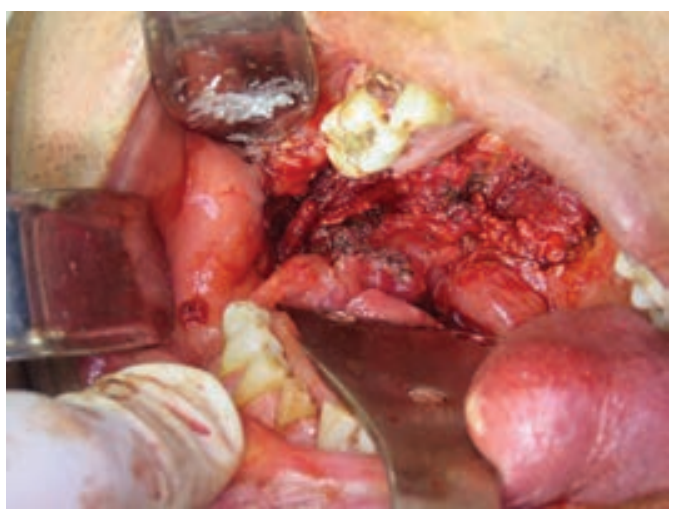

Figura 4: Procedimiento quirúrgico.

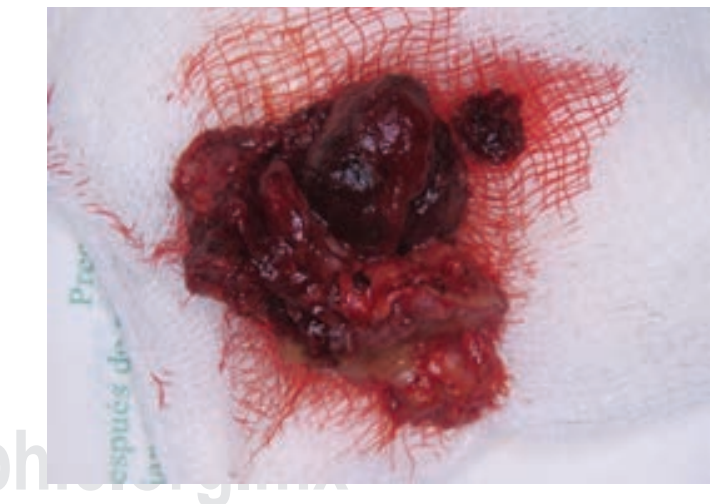

Figura 5: Escisión completa de la lesión.

Se debe establecer un diagnóstico diferencial mediante la citología, de una glándula salival o hiperplasia, debido a que la celularidad acinar monótona de los carcinomas de células acinares, bien diferenciados, es muy semejante a la celularidad acinar normal. El diagnóstico diferencial del tumor 
incluye carcinoma mucoepidermoide, adenoma pleomórfico, carcinoma adenoide quístico, lesión linfoepitelial benigna, linfadenoma sebáceo, sialoadenosis, sialoadenitis causada por radioterapia y linfadenitis. ${ }^{15}$

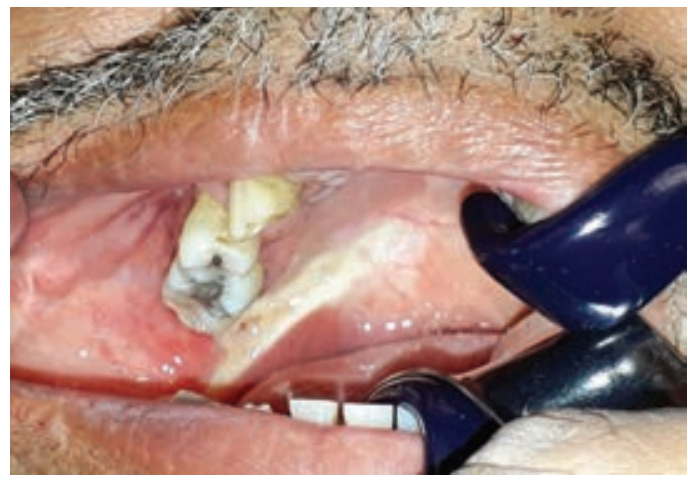

Figura 6: Once meses de evolución.

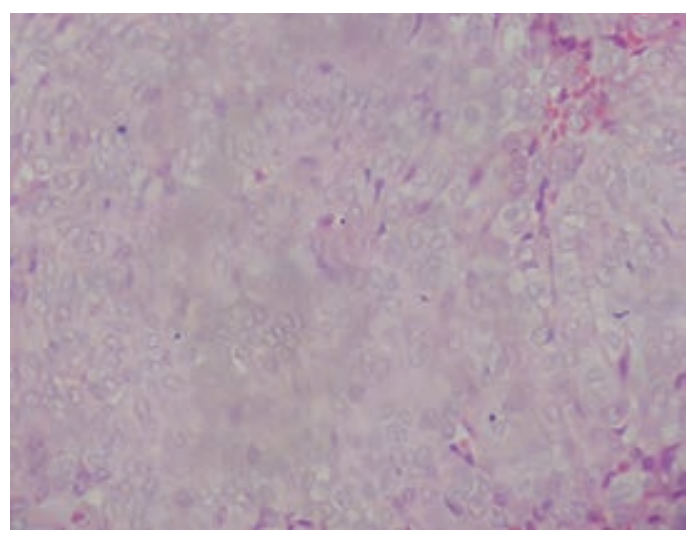

Figura 7: Carcinoma de células acinares patrón sólido.

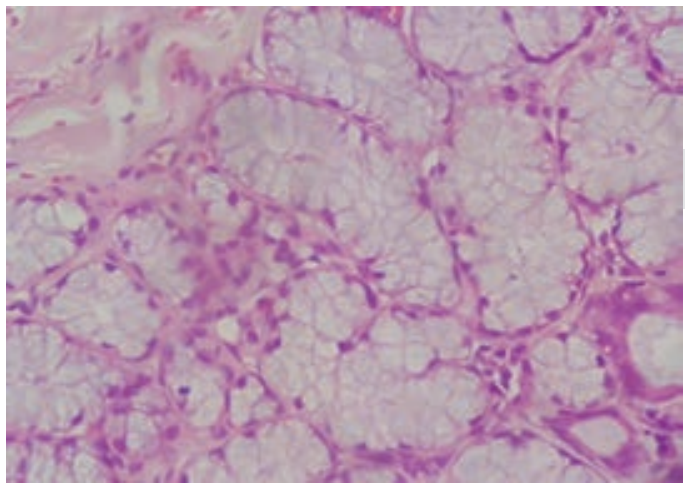

Figura 8: Cortes de células acinares con distribución histológica habitual.

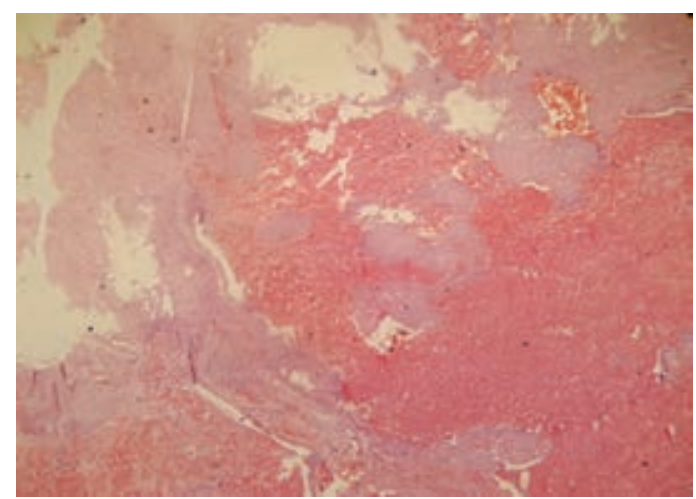

Figura 9: Carcinoma de células acinares con áreas hemorrágicas periféricas.

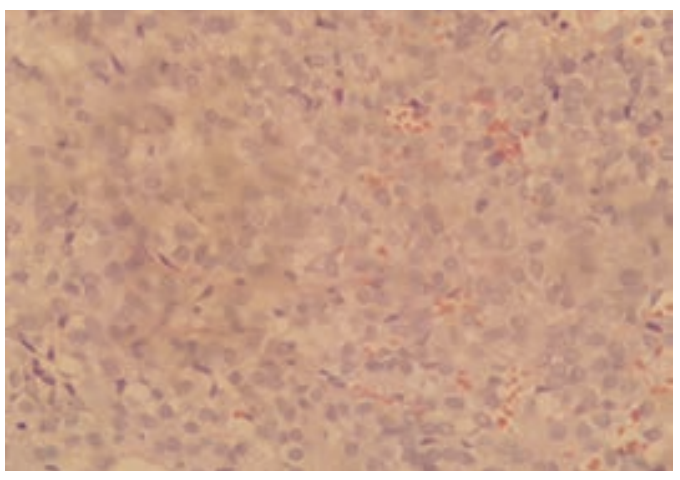

Figura 10: Células acinares con escasa mitosis encapsulada y delimitada.

El tratamiento de elección es la exéresis quirúrgica con márgenes amplios, con terapias accesorias; ${ }^{6}$ la radioterapia (RT) y disección de nódulos linfáticos son una alternativa opcional del tratamiento. La RT es la terapia adjunta de elección a la cirugía en casos clínicamente agresivos. ${ }^{14}$

Basado en la literatura, el caso clínico presentado difiere debido a que se presenta en glándula menor localizada en velo palatino, de crecimiento rápido, no dolorosa y sangrante al menor estímulo, con áreas de necrosis.

\section{REFERENCIAS}

1. Sapp P. Patología oral y maxilofacial contemporánea. $2^{\underline{a}}$ ed., 2005, Madrid: Elservier, España ISBN 8481747890.

2. Franco C, Torres OJ, Rodríguez GP, González AI, Volpato VR. Carcinoma de células acinares: gradación histológica. Rev Chilena de Cirugía. 2003; 55 (2): 132-135.

3. Prieto RM, Artés MMJ, Navarro HM, Camañas SA, VeraSempere FJ. Características citopatológica del carcinoma de células acinares (CCA) de glándula salival. A propósito de cuatro observaciones. Med Oral Patol Oral Cir Bucal. 2005; 10: 103-108. 
4. Castro CMC, Reyes MOL. Carcinoma de células acinares. Reporte de caso y revisión de literatura. Revista Médica Carrionica. 2016; 3 (2): 138.

5. Bircan S, Kayaselcuk F, Yavuz H, Tuncer I. Acinic cell carcinoma whit folicular pattern of the soft plate. Pathol Res Pract. 2004; 200: 575-579.

6. Triantafillidoy K, Iordanidis F, Psomaderis K, Kalimera E. Acinic cell carcinoma of minor salivary glands: a clinical and immunohistochemical study. J Oral Maxillofac Surg. 2010; 68: 2489-2496.

7. Kaneko H, Yano H, Owada M, Fujibayashi M, Abe H. Acinic cell carcinoma arising in the buccal mucosa: a case report of specific type of papillary-cystic variant. J Oral Maxillofac Surg Med Pathol. 2014; 26 (3): 411-414.

8. Omilie JE, loannis GIK. Acinic cell carcinoma of minor salivary glands: a clinicoplathologic study of 21 cases. J Oral Maxillofac Surg. 2010; 68: 2053-2057.

9. Batsakis J, Luna M, El-Naggar A. Histopathologic grading of salivary gland neoplasms: II. Acinic cell carcinoma. Ann Otol Rhinol Laryngol. 1990; 99: 929-933.
10. Olivera P, Fonseca I, Soares J. Acinic carcinoma of the salivary glands. A long term follow-up study of 15 cases. Eur J Surg Oncol. 1992; 18 (1): 7-15.

11. Timon CI, Dardick I, Panzarella T, Patterson B, Thomas MJ, Ellis GL, Gullane PJ. Acinic cell carcinoma of salivary glands. Prognostic relevance of DNA flow cytometry and nucleolar organizer regions. Arch Otolaryngol Head Neck Surg. 1994; 120 (7): 727-733.

12. Shah A, Patwari M, Deshmukh RS. Acinic cell carcinoma, papillarycystic variant of the patoid gland: A case report with review of literatura. Oral Oncology Extra. 2005; 41: 137-141.

13. Koyuncu M, Atmaca S, Kandemir B, Cakil B. Acinic cell carcinoma in minor salivary glands of retromolar trigone. OMU Tip Dergist. 2008; 25 (2): 72-74.

14. Esteban AR, Samar ME, Camps D, Fernández R, Fernández JE. Tumores de glándulas salivales menores. Estudio retrospectivo de 46 casos. Rev Esp Patol. 2008; 41 (1): 23-29.

15. Nagel H, Laskawi R, Jürgen BJ, Schroder M, Chilla R, Droese M. Cytologic diagnosis of acinic-cell carcinoma of salivary glands. Diagn Cytopathol. 1996; 16 (5): 402-410. 